\title{
FLOW IN FIREFIGHTERS AND ITS RELATIONSHIP WITH PERFORMANCE IN HIGH-RISK TASKS: PRELIMINAR RESEARCH
}

\author{
Ricardo DE LA VEGA'), Jorge Pérez GARCÍA ${ }^{2)}$, \\ Roberto RUIZ-BARQUÍN ${ }^{3)}$, and Sara MÁRQUEZ ${ }^{4)}$ \\ ${ }^{1)}$ Department of Physical Education, Sport and Human Movement, Universidad Autónoma de Madrid, Spain \\ ${ }^{2)}$ Firefighters Brigade, Poniente de Almeria, Spain \\ ${ }^{3)}$ Department of Development Psychology and Education, Universidad Autónoma de Madrid, Spain \\ ${ }^{4)}$ Institute of Biomedicine (IBIOMED) and Department of Physical Education and Sport, \\ Universidad de León, Spain
}

\begin{abstract}
Flow is an operational mental state in which people is fully immersed in a performed activity. The aim of this study was to measure in professional firefighters flow and its relationship with performance in tasks with a high risk component. The state of flow was assessed by the Flow State Scale (FSS) in six professional firefighters during a simulation of a traffic accident (STA), together with their expected and perceived performance. Results indicated that firefighters reached high levels of flow during their work performance in risky tasks potentially generating high levels of stress. Adequate performance values and a positive correlation between flow and expected or perceived performance were obtained. Quantitative results were complemented by qualitative interviews after STA. Data obtained emphasize the relevance of flow study in those professions involving conditions of high risk.
\end{abstract}

Key words: Flow, firefighters, risk, performance

\section{INTRODUCTION}

The concept of flow was developed by Csikszentmihalyi in the 1970s (Csikszentmihalyi, 1979). It is considered a state of optimal experience that involves a total absorption in the task being performed, as well as the creation of a state of concentration that facilitates the emergence of optimum performance (Csikszentmihalyi, 1990; GarcíaCalvo, Jiménez, Santos-Rosa, Reina, \& Cervelló, 2008). Csikszentmihalyi (1990) and Jackson and Csikszentmihalyi (2002) specify the existence of nine flow state dimensions: balance between skill and challenge, merging of action/awareness, clear goals, clear direct feedback, concentration on the task being performed, sense of control, loss selfconsciousness, distorted sense of time and autothelic experience. When considering those dimensions, a series of characteristics may be established linking the situation and the task in which the subject would have a greater willingness to reach states of flow and, consequently, optimum performance.

\footnotetext{
This research was framed into the Master Degree in High Performance by the Spanish Olympic Committee (COE-UCAM).

Correspondence concerning this article should be addressed to Ricardo de la Vega, Department of Physical Education, Sport and Human Movement, Universidad Autónoma de Madrid, address, Spain (e-mail: delavegaricardo@hotmail.com).
} 
Currently, there are few studies that measure flow state and its relationship with performance in situations far from the dimensions proposed by Csikszentmihalyi. Only researchs on white-water canoeists (Sparkes \& Partington, 2003) or big-wave surfers (Partington, Partington, \& Olivier, 2009) have analyzed flow in conditions in which the athlete does not have control over the task or in which the requirement level of the task exceeds his/her ability. In the context of studies of firefighters, it is worth highlighting Chen-Lin's recent work (2014), which concludes that flow state has a positive influence on work satisfaction in volunteer firefighters. However, studies about this topic have not been performed in professional firefighters (De la Vega, Ruiz, Gómez, \& Rivera, 2013).

With respect to research on flow state and performance, several studiess have found positive relationships between both variables, especially in the field of sport (Jackson 1992, 1995, 1996; Jackson, Thomas, Marsh, \& Smethurst, 2001). Concerning flow in situations or tasks generating stress, which are the focus of our work, research has been conducted to evaluate flow, anxiety and their relationship with performance; low levels of anxiety were detected in associationto good performance and flow experiences, suggesting that anxiety negatively affects the feeling of flow and, consequently, performance (Jackson et al., 2001; López-Torres, Torregrosa, \& Roca, 2007).

The present investigation was aimed to assess flow state and performance in a very specific context that has not been analyzed previously but is of a great importance and social impact: the response to traffic accidents of firefighter teams, which in Spain are usually made up of six people. We were interested in knowing whether flow states can be reached in a simulated situation with a high emotional-impact level -responding to a traffic accident- and with high stress and risk loads for both the involved individuals and third parties Additionally, we analyzed if the possibility of reaching high performance levels related to the feeling of being in flow states.

\section{METHOD}

\section{Participants}

The sample comprised six Spanish firefighters from the Poniente Almeriense fire brigade. They were all male and aged between 28 and 55 years $(M=39.5, S D=9.65)$. Experience of the subjects as firefighters ranged between 4 and 25 years $(M=14.0, S D=8.63)$.

\section{Instruments}

To collect information on flow state, we used the Flow State Scale (FSS; Jackson \& Marsh, 1996), and specifically the Spanish adaptation validated by García-Calvo et al. (2008). The scale is structured according to the nine dimensions, each including four items, discussed earlier. The answers are based on a 10-point Likert scale, from 1 (totally in disagreement) to 10 (completely in agreement). All dimensions have internal consistencies higher than 70, which considered as appropriate values (Nunnally, 1978).

Performance expectation was assessed through the use of a question that asked subjects to indicate on a scale of 10 points if they felt prepared to produce the best possible performance in the emergency situation that they would perform. Once the test had been carried out, they responded again to the question to see how they perceived their performance. Furthermore, performance was externally assessed by two experienced observers who viewed the test in situ and scored the participants' performance on an individual basis using a scale of 1 to 10 points. Data were complemented by semi-structured interviews performed after the simulation of the traffic accident, which were recorded and transcripted. 
Procedure

The study was carried out in the workplace during a day when the firefighters were on duty, for reasons of easy access to the full sample. Managers and participants were informed of the nature of the research and tests that were to be done, fulfilling the ethical requirements of the Helsinki Declaration. All participants gave their written consent to participate in the study.

To measure the flow and performance variables, we prepared a situation that was as real as possible. Tasks most stressful and demanding firefighters to act with great speed and performance are traffic accidents. Therefore, in order to resemble a real situation as much as possible, we prepared a vehicle that was tipped onto its side, and a person playing the role of a victim was trapped inside. The firefighters did not know the type of accident or situation that they were to be placed in until they arrived at the area where the simulation was being carried out.

Participants were applied the FSS and responded to the question on performance before and after the completion of the test. Semi-structured interviews were also performed to know the opinion of participants on reasons for their expectation of performance before the STA (EBS), aspects considered relevant to improve their flow scores related to STA (IFS), reasons for their performance perception after the STA (EAS), and aspects considered relevant to improve performance (IPS).

\section{Data analysis}

Mean and standard deviation were calculated for the different variables. The interjudge reliability of the two observers with respect to the performance of the firefighters was calculated using the kappa index. Relationship between the results in the FSS and the pre-test expectation of performance, post-test performance perception evaluation or the performance evaluation of both observers was measured using Spearman's correlation. To find out whether there were differences between pre-test expectation of performance and posttest perception of performance, Wilcoxon's rank test was performed. Statistical analysis was conducted using SPSS 20.0. Interpretative Phenomenological Analysis (IPA) was used to try to understand the experiences of individual firefighters in relation to their perceived performance; answers were organized into superordinate cathegories according to Smith (1996).

\section{RESULTS}

Results for the flow state (Table 1) indicate elevated average values in all scales (above 7 points). To analyze the interjudge reliability of the two observers, the kappa index

Table 1. Mean and standard deviation of the different flow dimensions.

\begin{tabular}{lll}
\hline \multicolumn{1}{c}{ Factors } & $M$ & $S D$ \\
\hline Ability level/Challenge & 7.66 & 1.14 \\
Merging of action & 7.04 & 1.44 \\
Clear goals & 8.41 & 1.11 \\
Clear direct feedback & 7.58 & 1.32 \\
Sense of control & 9.12 & 1.34 \\
Concentration on task & 8.00 & 1.57 \\
Loss of self-consciousness & 7.08 & 2.57 \\
Distorted sense of time & 7.41 & 2.08 \\
Autothelic experience & 7.70 & 2.26
\end{tabular}


Table 2. Relationship between performance and flow.

\begin{tabular}{lllll}
\hline & PPP & EO1 & EO2 & FSS \\
\hline Pre-test expectation of performance (PEP) & $.953^{* *}$ & -.317 & .433 & $.772^{*}$ \\
Post-test performance perception (PPP) & & -.286 & .429 & .618 \\
Evaluation of performance of observer 1 (EO1) & & & .583 & .185 \\
Evaluation of performance of observer 2 (EO2) & & & & .648 \\
\hline
\end{tabular}

$* * p<.01 ; * p<.05$

was calculated, providing a high value $(k=.83)$. Once the calculation of interjudge reliability had been completed, it was determined if there were significant differences between the EBS and the perception of subsequent performance. We found that the values did not differ significantly $(p=.56)$.

Table 2 shows the correlation analysis between the pre-test expectation of performance (PEP), the post-test performance perception (PPP), the evaluation of the performance of observers1 (EO1) and the evaluation of the performance of observers2 (EO2) and the total score on the FSS. Results obtained show a moderate positive relationship between the pretest performance expectations and the total flow score $(p<.05)$. A high correlation between pre-test performance expectations (PPE) and post-test self-assessment of performance (PPP) was also found $(p<.01)$. There was no relationship between the two observers' assessments (EO1 and EO2) and any of the firefighters' performance measures or the final flow score $(p>0.05)$. Fig. 1 and 2 show correlation plots that give a more detailed look into the nature of correlations between PEP and FSS total score, or PPP and FSS total score.

Correlation analyses considering the nine FSS scale factors are depicted in Table 3. In contrast to the previous table, statistically significant correlations of PPE and post-test self-evaluation of performance (PPP) with the FSS subfactors balance between ability level and challenge, merging of action, clear goals, clear direct feedback and concentration were obtained. No significant correlation existed with the subfactors loss of selfconsciousness, time distortion and autothelic experience. Neither correlations were detected between the performance evaluation of the two observers and the FSS subfactors.

PPE correlated significantly and positively with the factors merging of action, clear goals, clear direct feedback and sense of control $(p<.01)$, and with balance between ability level/challenge and concentration $(p<.05)$. Regarding the post-test perceived performance (PPP), significant correlations were obtained with the factors clear direct feedback $(p<.001)$, ability level/challenge, sense of control and concentration $(p<.01)$. Although significant correlations were not detected, data tended toward statistical significance in the factors merging of action and clear goals $(p<.10)$. Finally, no significant relationships were observed between the FSS factors and the performance ratings of the two observers.

Regarding qualitative analysis, the categories that emerged from each questions were the following: EBS: Perception of control, experience, previous training; IFS: Automatic 


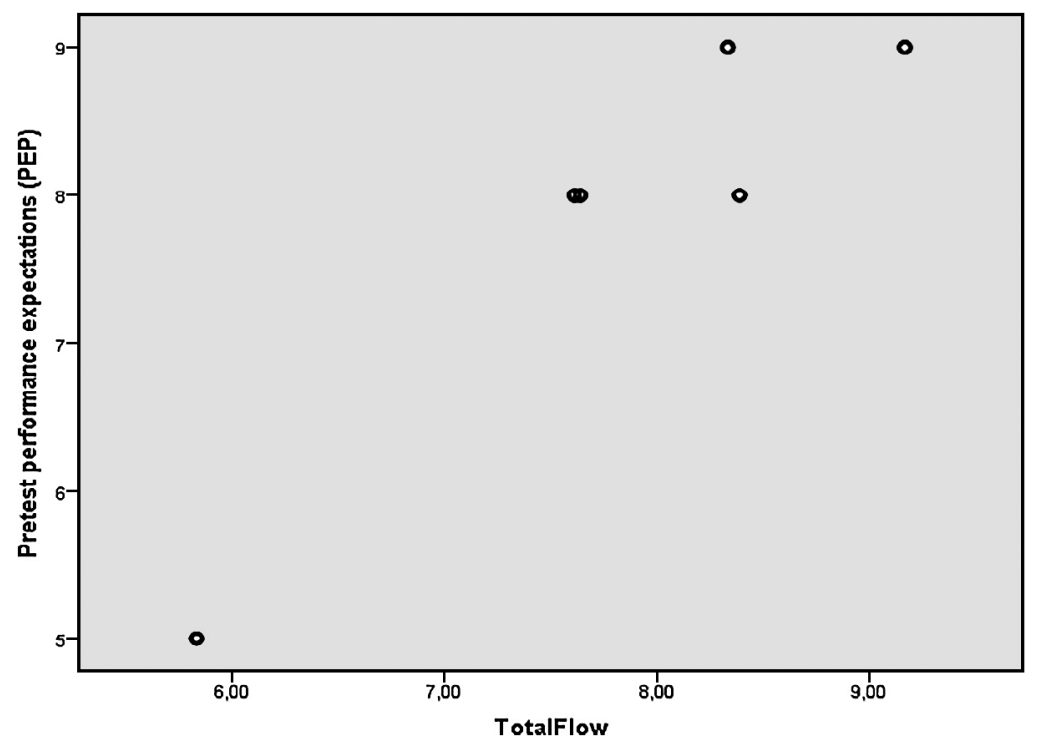

Fig. 1. Correlation plot among pre-test expectation of performance (PEP) and FSS total score (Total Flow).

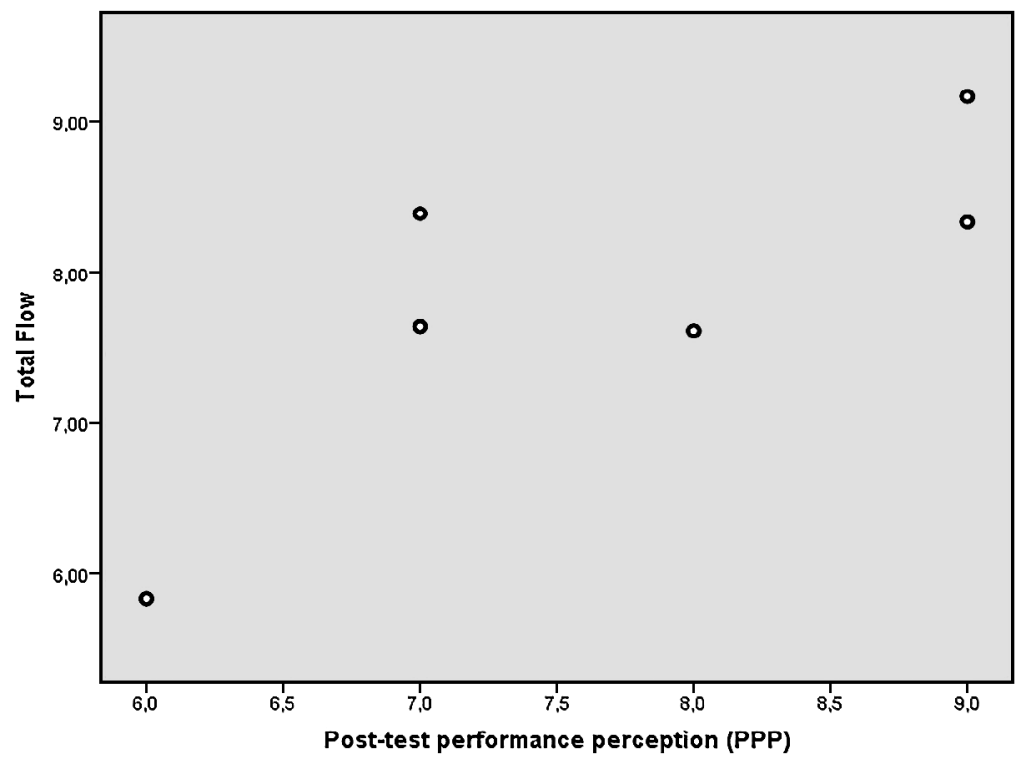

Fig. 2. Correlation plot among post-test performance perception (PPP) and FSS total score (Total Flow).

answer, more training, feeling team performance, greater confidence; EAS: Duty fulfilled, do everything I expected; and IPS: More training, best materials, motivation. The firefighter getting the lowest scores attributed results to low motivation, perception of teamwork and existing material resources. This perception contrasts with that from colleagues, who have 
Table 3. Relationship between performance and the different flow dimensions.

\begin{tabular}{lllll}
\hline & PEP & PPP & EO1 & EO2 \\
\hline Ability level/Challenge & $.861^{*}$ & $.940^{* *}$ & .016 & .564 \\
Merging of action & $.926^{* *}$ & $.794^{\dagger}$ & -.093 & .525 \\
Clear goals & $.926^{* *}$ & $.794^{\dagger}$ & -.247 & .525 \\
Clear direct feedback & $.926^{* *}$ & $.971^{* * *}$ & -.062 & .555 \\
Sense of control & $.926^{* *}$ & $.971^{* *}$ & -.062 & .555 \\
Concentration on task & $.820^{*}$ & $.938^{* *}$ & -.066 & .590 \\
Loss of self-consciousness & .648 & .441 & .185 & .494 \\
Distorted sense of time & .463 & .441 & .494 & .648 \\
Autothelic experience & .000 & .090 & .204 & .360 \\
\hline
\end{tabular}

$* * * p<.001 ; * * p<.01 ; * p<.05 ;{ }^{\dagger} p<.10$

Table 4. Examples of qualitative interview answers. The firefighters were listed by years of experience (highest to lowest).

\begin{tabular}{|c|c|c|c|c|}
\hline & EBS & IFS & EAS & IPS \\
\hline Firefighter 1 & $\begin{array}{l}\text { "I have control over } \\
\text { the simulation" }\end{array}$ & $\begin{array}{l}\text { "Do not think, just } \\
\text { act" }\end{array}$ & $\begin{array}{l}\text { "I felt like it, I don't } \\
\text { know" }\end{array}$ & $\begin{array}{l}\text { "Perhaps even more } \\
\text { training" }\end{array}$ \\
\hline Firefighter 2 & $\begin{array}{l}\text { "I know exactly } \\
\text { what I should do" }\end{array}$ & $\begin{array}{l}\text { "Train it at least } \\
\text { once a week" }\end{array}$ & $\begin{array}{l}\text { "It's complex to } \\
\text { explain, but I think } \\
\text { that I did it well" }\end{array}$ & $\begin{array}{l}\text { "Have better } \\
\text { materials" }\end{array}$ \\
\hline Firefighter 3 & $\begin{array}{l}\text { "I have a lot of } \\
\text { experience and can } \\
\text { be very useful to" }\end{array}$ & $\begin{array}{l}\text { "Trust that } \\
\text { everything will be } \\
\text { fine" }\end{array}$ & $\begin{array}{l}\text { "I did my duty and I } \\
\text { think that } \\
\text { everything went } \\
\text { well" }\end{array}$ & $\begin{array}{l}\text { "Coordinate a little } \\
\text { more as a team" }\end{array}$ \\
\hline Firefighter 4 & $\begin{array}{l}\text { "I have lived similar } \\
\text { real situations and } \\
\text { train them is } \\
\text { essential" }\end{array}$ & $\begin{array}{l}\text { "Feel that together } \\
\text { we give the } \\
\text { maximum" }\end{array}$ & $\begin{array}{l}\text { "I did everything I } \\
\text { had to do" }\end{array}$ & $\begin{array}{l}\text { "Full trust in the } \\
\text { other" }\end{array}$ \\
\hline Firefighter 5 & $\begin{array}{l}\text { "I have much } \\
\text { control over what } \\
\text { we do" }\end{array}$ & "Act automatically" & $\begin{array}{l}\text { "I did everything I } \\
\text { had trained" }\end{array}$ & $\begin{array}{l}\text { "Give the maximum } \\
\text { we can" }\end{array}$ \\
\hline Firefighter $6^{*}$ & $\begin{array}{l}\text { "The last two } \\
\text { simulations did not } \\
\text { do well. I had little } \\
\text { motivation" }\end{array}$ & $\begin{array}{l}\text { "I should be more } \\
\text { convinced. } \\
\text { Teamwork" }\end{array}$ & $\begin{array}{l}\text { "I knew what was } \\
\text { going to happen" }\end{array}$ & $\begin{array}{l}\text { "Be more } \\
\text { motivated. Have } \\
\text { better material } \\
\text { resources" }\end{array}$ \\
\hline
\end{tabular}

* Firefighter with the lowest PPT and total flow score. 
perceptions of greater control, yet also realizing that the material resources and training could be further improved.

\section{DISCUSSION}

Our research was aimed to reach two objectives. The first was to measure the situational flow of firefighters in a simulation of a traffic accident. While, due to their characteristics, the tasks undertaken by firefighters in high-risk situations would not seem to facilitate or promote the emergence of flow states, in our study we found high values. This is in the line of the suggestion by Stranger (1999) that risk seems to constitute a fundamental catalyst for achieving flow states. This is a key factor for future research on the flow construct and one that can be extrapolated to extreme sports. The strong need for achievement and a task oriented towards specific targets could justify the values obtained in the present study, since they correspond to the most important features of the work undertaken by firefighters.

Our second objective was to measure the relationship between flow state and performance in the task. In this case, a positive relationship between the two variables was found when both, expectations relating to performance and post-task perceptions of performance, were considered. This finding supports previous studies, especially those in the sports field, that have shown how athletes are able to experience episodes of flow during their performance, especially when they have an intrinsic motivation and a high level of perceived efficiency (López-Torres et al., 2007). Other authors have also found positive relationships between states of flow and performance in the workplace. Thus, Eisenberger, Jones, Stinglhamber, Shanock, and Randall (2005) highlighted how in the case of employees from various companies there was a positive relationship between flow and performance in those who were task oriented. Li-Chuan and Chen-Lin (2012) have shown that in primary-school teachers, flow has a positive impact on performance, with the relationship influenced by moderating there being moderating factors such as emotional stability.

Regarding pre-test expectations of results and post-test self-assessment, factors for which there was no statistically significant relationship were "loss of self-consciousness," "time distortion" and "autothelic experience". Unlike some studies carried out in the field of sport (García-Calvo et al., 2008), in the case of high-risk professions such as firefighting, a strong relationships between these three factors, expectations of results and selfassessment of performance could be counterproductive, since in many cases complex decisions requiring the conscious and explicit implementation of cognitive processes need to be taken. More specifically, a "loss of self-consciousness" has a higher probability of occurring in cognitive, motor and behavioral processes that are highly automated and that do not require a fight-or-flight response to serious risk for the person or others (which is the case in the vast majority of sports), and above all in emergency situations with high uncertainty (risk of explosion, uncontrolled spread of fire, etc.). Meanwhile, time is a factor decisive in both sport and high-risk professions. One of the differences with respect 
to the majority of sports is that in high-risk professions, errors may have life-or-death consequences. Consciousness of time is in these cases of critical importance for both the professional and for his/her team, as well as for the people who may potentially be directly or indirectly involved in a particular risk situation. Finally, open-ended and highly uncertain situations, coupled with elevated psychophysiological stress levels, reduce the probability that professionals such as firefighters enjoy the activity as it is being carried out ("autothelic experience").

Although these three factors had scores between 7.08 and 7.70 points (out of 10), they received the lowest scores along with the subfactors "balance between ability level and challenge" and "merging of action". In addition to the limitation that supposes the small number of participants in the study, data could indicate the need to establish specific standards or to design specific tests for firefighters with the aim of evaluating professionals in their reference group and avoiding comparisons with other populations (such as athletes). It will also be important for subsequent studies to evaluate multiple types of interventions not limited to the simulation of an accident (such as rescues at height, fires in buildings, etc.), given that there may be significant individual differences in the firefighter population due to differential levels of competence in each of the possible situations.

Regarding the relationship of the assessments of the two observers with the firefighters' flow states, pre-test performance expectations and post-test self-assessment of performance, this study shows that flow is an individual and internal process of the individuals. Moreover, an absence of relationship here may be due on the one hand again to the low number of participants, and on the other to the difficult to find pecific behavioral parameters that may be considered objective indicators of the presence of flow.

We are aware of the complexity and the limitations of the study because of the reduced sample used. However, results obtained may be relevant to future research, assuming there is a merit in working with a population that is so specific and difficult to access for research studies. Future research should focus on understanding more in depth and with larger samples factors that enable or facilitate the existence of high flow values in a task apparently far from the typical tasks proposed when this construct was conceived.

\section{REFERENCES}

Chen-Lin, L. 2014. Adopting the perspective of flow to investigate the effects of participation motivation on volunteer firefighters' job satisfaction. The Journal of International Management Studies, 9, 113-125.

Csikszentmihalyi, M. 1979. The concept of flow. In B. Sutton-Smith (Ed.), Play and learning (pp. 335-358). New York, NY: Halsted Press.

Csikszentmihalyi, M. 1990. Flow: The psychology of optimal experience. New York, NY: Harper \& Row.

De la Vega, R., Ruiz, R., Gómez, J., \& Rivera, O. 2013. Hardiness in professional Spanish firefighters. Perceptual \& Motor Skills, 117, 608-614. doi: 10.2466/15.PMS.117x19z4

Eisenberger, R., Jones, J., Stinglhamber, F., Shanock, L., \& Randall, A. 2005. Flow experiences at work: For high need achievers alone? Journal of Organizational Behavior, 26, 755-775. doi: 10.1002/job.337

García-Calvo, T., Jiménez, C. R., Santos-Rosa, F., Reina, R., \& Cervelló, E. 2008. Psychometric properties of the Spanish version of the Flow State Scale. The Spanish Journal of Psychology, 11, 660-669.

Jackson, S. A. 1992. Athletes in flow: A qualitative investigation of flow states in elite figure skaters. Journal of Applied Sport Psychology, 4, 161-180. doi: 10.1080/10413209208406459 
Jackson, S. A. 1995. Factors influencing the occurrence of flow in elite athletes. Journal of Applied Sport Psychology, 7, 138-166. doi: 10.1080/10413209508406962

Jackson, S. A. 1996. Toward a conceptual understanding of the flow experience in elite athletes. Research Quarterly for Exercise and Sport, 67, 76-90.

Jackson, S. A., \& Csikszentmihalyi, M. 2002. Fluir en el deporte. Claves para las experiencias y actuaciones óptimas [Flow in sport. Keys to optimal experience and performance]. Barcelona, Spain: Paidotribo.

Jackson, S. A. \& Marsh, H. W. 1996. Development and validation of a scale to measure optimal experience: The Flow State Scale. Journal of Sport and Exercise Psychology, 18, 17-35. doi: 10.1123/jsep.18.1.17

Jackson, S. A., Thomas, P. R., Marsh, H. W., \& Smethurst, C. J. 2001. Relationships between flow, selfconcept, psychological skills, and performance. Journal of Applied Sport Psychology, 13, 129-153. doi: 10.1080/104132001753149865

Li-Chuan, C., \& Chen-Lin, L. 2012. Exploring the impact of flow experience on job performance. The Journal of Global Business Management, 8(2), 150-158.

López-Torres, M., Torregrosa, M., \& Roca, J. 2007. Características del "Flow", ansiedad y estado emocional, en relación con el rendimiento de deportistas de elite. Cuadernos de Psicología del Deporte, 7(1), $25-44$.

Nunnally, J .C. 1978. Psychometric theory. New York, NY: McGraw-Hill.

Partington, S., Partington, E., \& Olivier, S. 2009. The dark side of flow: A qualitative study of dependence in big wave surfing. The Sport Psychologist, 23, 170-185.

Smith, J.A. 1996. Beyond the divide between cognition and discourse: Using interpretative phenomenological analysis in health psychology. Psychology \& Health, 11, 261-271.

Sparkes, A. C., \& Partington, S. 2003. Narrative practice and its potencial contribution to sport psychology: The example of flow. The Sport Psychologist, 17, 293-317.

Stranger, M. 1999. The aesthetics of risk: A study of surfing. International Review for the Sociology of Sport, 34, 265-276. doi: 10.1177/101269099034003003

(Manuscript received 19 January, 2016; Revision accepted 26 May, 2016) 